\title{
Metodologia para marca pessoal
}

\author{
Methodology for personal branding
}

\author{
ALMEIDA, Andréa; Doutora; Universidade Presbiteriana Mackenzie \\ andrea.almeida@mackenzie.br \\ CASTANHA Jr., Marcos Aurélio; Mestre; Universidade Presbiteriana Mackenzie \\ marcosaurelio.castanha@mackenzie.br
}

\section{Resumo}

A marca pessoal é um projeto de identidade visual que expressa uma série de valores e atributos necessários à sua configuração. A metodologia de projeto para o desenvolvimento da marca pessoal provém de reflexões de autores de design de identidade mesclado à experiência de mercado dos docentes envolvidos. Projetar nesta condição é muitas vezes um grande desafio para o estudante de design, já que ele é a própria fonte detentora de toda a informação para gerar o conteúdo deste sistema visual. No período de dez anos pôde-se construir uma percepção sobre o ato de realizar estes projetos, e também refletir sobre a evolução desta prática em sala de aula, nos cursos de design na cidade de São Paulo. O resultado foram projetos criativos e bem normatizados, onde alguns ex-alunos, hoje designers, fazem uso do sistema de identidade desenvolvido para suas marcas pessoais.

Palavras Chave: design; metodologia; marca pessoal.

\begin{abstract}
A personal brand is a visual identity that expresses a set of values and attributes required for it configuration. The design methodology for the development of personal brand comes from thinking about identity design authors joined with the market experience of the involved professors. Projecting in this condition is often a major challenge for design students, since they are the real source that holds all the information to generate the contents of the visual system. In 10 years it was possible to build a perception about the act of performing these projects, and also to think about the evolution of this practice in the classroom, at design schools in São Paulo. The result are creative and well ruled projects, and some former students, now designers, make use of the identity system developed for their personal brand.
\end{abstract}

Keywords: design; methodology; personal brand. 


\title{
1 Introdução
}

O tema em questão, identidade e marca pessoal, destina-se a refletir sobre a necessidade do significado da construção da identidade pessoal na contemporaneidade, em virtude das mudanças ocorridas neste cotidiano moderno líquido, conforme aponta Benedito Vecchi na introdução da entrevista realizada a Zygmunt Bauman:

\begin{abstract}
A questão da identidade também está ligada ao colapso do Estado de bem-estar social e ao posterior crescimento da sensação de insegurança, com a "corrosão do caráter" que a insegurança e a flexibilidade no local de trabalho têm provocado na sociedade. Estão criadas as condições para o esvaziamento das instituições democráticas e para a privatização da esfera pública, que parece cada vez mais um talk-show em que todo mundo vocifera as suas próprias justificativas sem jamais conseguir produzir efeito sobre a injustiça e a falta de liberdade existentes no mundo moderno. (BAUMAN, 2005, p.11)
\end{abstract}

O fato e a oportunidade de trabalhar com alunos em cursos superiores de design da cidade de São Paulo, cujo mercado é um dos mais promissores no campo do design gráfico e da identidade visual e corporativa brasileira, possibilitou a reflexão e o entendimento dado à disciplina de projeto identificar. Inicialmente o foco era a discussão e entendimento sobre o conceito e características da identidade visual, corporativa e pessoal. Mas no decorrer dos anos e experimentos projetuais, foi observado que a assimilação e prática dos projetos de identidade mercadológica eram fluidos e tranqüilos, enquanto o de identidade pessoal gerava um clima angustiante e conseqüentemente, questionador e reflexivo. Assim, os experimentos de métodos e didáticas específicas de cada docente envolvido, foram fundamentais para que o projeto alcançasse um nível maior do que a sua efetivação, resultando no pensamento do papel do futuro designer na sociedade, e na capacidade de intervenção no contexto político e operacional que o design tem e, deve questionar através de projetos que movimentem a ação efetiva dos indivíduos.

Desta forma, a percepção que este projeto de identidade pessoal detém vai muito além do encontro de uma configuração formal equilibrada, isto é, o logotipo pessoal, ele desperta e promove uma formação intelectual e a oportunidade do autoconhecimento, pois o aluno se depara com os seus próprios conflitos, seus dilemas, questionamentos, e ao mesmo tempo, tem que filtrar tudo isso e simbolizar num desenho coerente zo que deseja e necessita para a sua vida profissional. O percurso do projeto em certo sentido é a construção de uma identidade pessoal, e como tal, ele contém a prerrogativa do entendimento do que vem a ser identidade, já que ele estimula inicialmente a construção de uma persona, que segundo Jung (1983) é a personalidade que o indivíduo apresenta aos outros como real, mas que é uma variante às vezes diferente da verdadeira. E de certa forma, as pessoas utilizam deste recurso para serem incluídas em grupos, e terem uma inserção profissional, e muitas vezes entram em contradição com seus próprios valores. Para Jung (1983), a dissolução da persona é fundamental para o processo de individuação, por ser uma semelhança da personalidade, o ideal é o encontro da verdadeira essência do ser.

Atualmente o designer está cada vez mais sendo exigido no mercado de trabalho extremamente disputado, repleto de profissionais ávidos a desenvolverem trabalhos de qualidade. Diante disso, há a busca de uma diferenciação não só através de um método de trabalho, mas se faz necessário ter uma marca pessoal que possa representar a personalidade única, constituída de uma essência fundamentada por valores próprios e atributos bem delimitados. Lembrando que a atuação profissional hoje fundamenta-se por um comportamento 
humanitário e acima de tudo, ético. Colocar em questão o comportamento ético no meio profissional, e a sua relação intrínseca com a sociedade e os serviços necessários para vivermos coletivamente, mostra a complexidade deste assunto para o jovem estudante que por muitas vezes ainda está em busca de uma única resposta correta.

A maioria dos designers tem um método de trabalho que se baseia na sua concepção de design e em seus valores de sociedade, assim, consegue expressar visualmente suas conviç̧ões e mostrar suas ferramentas de trabalho, isto também justifica a necessidade da marca pessoal, além de contextualizar e fundamentar a linguagem visual a ser empregada. Uma marca pessoal não pode ser simplesmente um sinal gráfico, e sim, uma configuração visual que expresse de forma significativa as intenções do designer como indivíduo e profissional. Parafraseando Joan Costa, "a marca deve acima de tudo, significar e não simplesmente indicar" (COSTA, 2008, p.20).

Como diz o próprio nome, a marca pessoal é uma matriz genuína, pura e autêntica, e como tal, deve ser elaborada com muito cuidado, seu processo de construção tem que ser amadurecido seriamente, sem subterfúgios, é conveniente que o próprio designer a faça com muita conviç̧ão, para que consiga retratar as características pessoais com total clareza, percebendo as intenções e conhecimento dos verdadeiros significados utilizados. Para isso, o designer deve se entregar ao projeto com afinco, pois é um processo de autoconhecimento. Mas é necessário que o designer conheça as metodologias usuais de desenvolvimento do sistema de identidade visual e corporativa, justifique os conceitos e fundamentos específicos sobre o assunto, e principalmente, não caia na estratégia mercadológica, muitas vezes errônea, de construir uma marca sem propósito alinhada à sua essência.

Projetar é um ato de descolamento de um momento presente para um que ainda acontecerá, é antever uma situação gerando possibilidades de desenvolvimento de uma nova percepção para uma ideia, produto, serviço ou até mesmo uma experiência. O que esta prática e processo exige do designer é seu ponto de vista sobre algo, sua crença em um partido projetual, e desta forma, a sua expressão como ser humano é praticamente escancarada a todos. Parte deste profissional é exposta, sua intimidade como pessoa é revelada, querendo ou não, o projeto tem como maior função revelar e entregar exatamente a sua personalidade ou boa parte dela. Este percurso de ensino é apresentado e fundamentado por teorias pertinentes, sendo impactado por novas formas de enxergar o mundo. E passa a ser uma oportunidade também de discutir a educação e o ato de projetar, ação detentora e poderosa do ofício de um designer.

A metodologia utilizada neste desenvolvimento de marcas e projetos de identidade visual, tem respaldo teórico nos autores Alina Wheeler (2012), Joan Costa (2008), Marty Neumeier (2008), Delano Rodrigues (2011) e Rodolfo Fuentes (2006). Este último trabalhou juntamente com o professor Costa em sua trajetória e pesquisa sobre identidade de marca. A atividade de imersão e busca pelos sentimentos e valores do designer no processo de desenvolvimento da sua marca pessoal, faz um paralelismo com a escolha de atributos para uma plataforma de marca de uma empresa ou instituição. A condução desse processo criativo e regulatório, necessita de uma metodologia clara, segura e profunda para a construção da plataforma de marca e sua manifestação visual. Isto atrelado a um processo de regramento, conseqüentemente à construção de um manual de marca, ou carta gráfica, também assim chamada, que conduz o uso e manifestação da comunicação desenvolvida.

A dinâmica é muito intensa para os participantes deste projeto, pois sendo o objeto de 
estudo sua própria personalidade, seus valores e crenças, muitas vezes percebe-se o quanto novas descobertas e reflexões são deflagradas pelos participantes. Também é fato um certo incômodo em discutir pontos desfavoráveis, e que mesmo assim, precisam ser levados em conta na formulação de atributos para a identidade pessoal. O trato profissional, respaldado pela metodologia de construção de marca auxilia no processo de entendimento da proposta, levando a cada etapa os participantes a documentar as respostas obtidas sem perder ou distorcer dados, gerando um caminho de projeto freqüentemente inesperado. A marca pessoal é um exercício que de certa forma tem contribuído para iniciar e fortalecer determinadas posturas e condutas para os alunos, construindo um discurso e um posicionamento de marca e futuro profissional no mercado de trabalho.

No processo de pesquisa, o aluno é direcionado a levantar diversas marcas pessoais existentes, observar e entender conceitos visuais comuns em marcas pessoais de outros profissionais. O intuito é afastar a utilização de modismos gráficos e possibilitar o encontro de resultados coerentes. Como apontado anteriormente, a marca pessoal deve ter uma identidade própria, única e fiel às características de sua representação, se não for assim, ela não terá consistência e nem um tempo mínimo de permanência, que nos casos de marcas de empresas, varia em torno de 5 a 10 anos. Mas no caso da marca pessoal, o tempo de permanência vai de encontro ao objetivo que o designer busca na sua vida profissional, e de certa forma, como ele entende e trabalha a questão e função do design na sociedade.

A fase seguinte com este compêndio de informação, agora organizado, gera as possibilidades de configuração e caminhos de representação gráfica, os chamados estudos ou roughs, termo em inglês muito utilizado na área do design. As escolhas cromáticas e tipográficas também são atores desta etapa e como camadas sedimentam e fortalecem a identidade visual em processo. Esta fase do projeto tem como habitual andamento, exaustivos encontros para desenhar, discutir, apresentar e refazer, e posteriormente refinar muitas e muitas vezes até a satisfação, respostas devem ser sanadas na representação visual e desdobramentos possíveis revelados nas aplicações principais e secundárias. O processo de fechamento dos estudos, afunilamento de percepções e respostas, apontados por Alina Wheeler (2012) é o novo ponto de partida para se definir a imagem da marca e começar as suas tentativas e testes de aplicação em suportes e meios de propagação da manifestação da marca. É importante para o aluno entender que é preciso construir um habitat de marca, uma atmosfera para que ela possa ser compreendida em determinados contextos e situações.

A fase final do processo é a documentação de todo o desenvolvimento da marca, e mais que isso, servir pedagogicamente como um guia de uso do sistema de identidade em que se transformou o projeto.

Tem-se a consciência que uma marca pessoal não estará estampando embalagens em um supermercado, muito menos na fachada de uma loja qualquer, mas sim, ela vai representar a visão de um indivíduo que desenvolve projetos de objetos e/ou serviços para atender as necessidades de usuários. Isto carrega uma função complexa de percepção e incorpora elementos visuais, que posteriormente se transformarão em códigos específicos e que estarão presentes na identidade concebida.

\section{O Processo para construção da Marca Pessoal}

O desenvolvimento da marca pessoal passa por três etapas ou fases comuns aos processos 
de projeto, porém essas etapas são trabalhadas de maneira diferente, primeiro porque o projeto é pessoal, onde o designer além de ser o profissional executor é ao mesmo tempo o cliente, e como tal, deve interagir nos dois momentos. Este é o maior empecilho, e sendo um projeto acadêmico, os alunos ficam muito inseguros de tomar decisões imbuídas pela intuição, que na verdade é o grande mote deste processo, já que o pensamento racional coloca abaixo a questão sensível e delicada, fundamental para promover o autoconhecimento, que deve ser sutil e ao mesmo tempo, pontual e contundente.

As "identidades" flutuam no ar, algumas de nossa própria escolha, mas outras infladas e lançadas pelas pessoas em nossa volta, e é preciso estar em alerta constante para defender as primeiras em relação às últimas. Há uma ampla probabilidade de desentendimento, e o resultado da negociação permanece eternamente pendente. (BAUMAN, 2005, p.19)

A primeira etapa geralmente denominada de levantamento de informações, neste projeto configura-se com a construção dos cenários. Onde considera-se o presente, passado e futuro do aluno. O procedimento baseia-se em três questões: quem eu sou e o que me identifica? Como as pessoas me vêem? E como eu gostaria de ser visto? Essas questões são dadas aos alunos para que pensem um pouco, no prazo de uma a duas semanas. A ideia inicial é que eles construam cenários pessoais, utilizando uma linha do tempo que evidencie momentos de mudanças nas suas vidas, através de datas, desenhos, fotos e palavras-chave; é importante que esta linha do tempo tenha o momento exato do surgimento da idéia de ser um designer. Foram separados dois exemplos de cenários com características diferentes: na figura 1, a organização é racional, elaborado no computador; na figura 2, o cenário foi feito manualmente em sala de aula, é mais emocional. Os exemplos representam personalidades, características e objetivos únicos.

Figura 1 - Cenário com organização racional

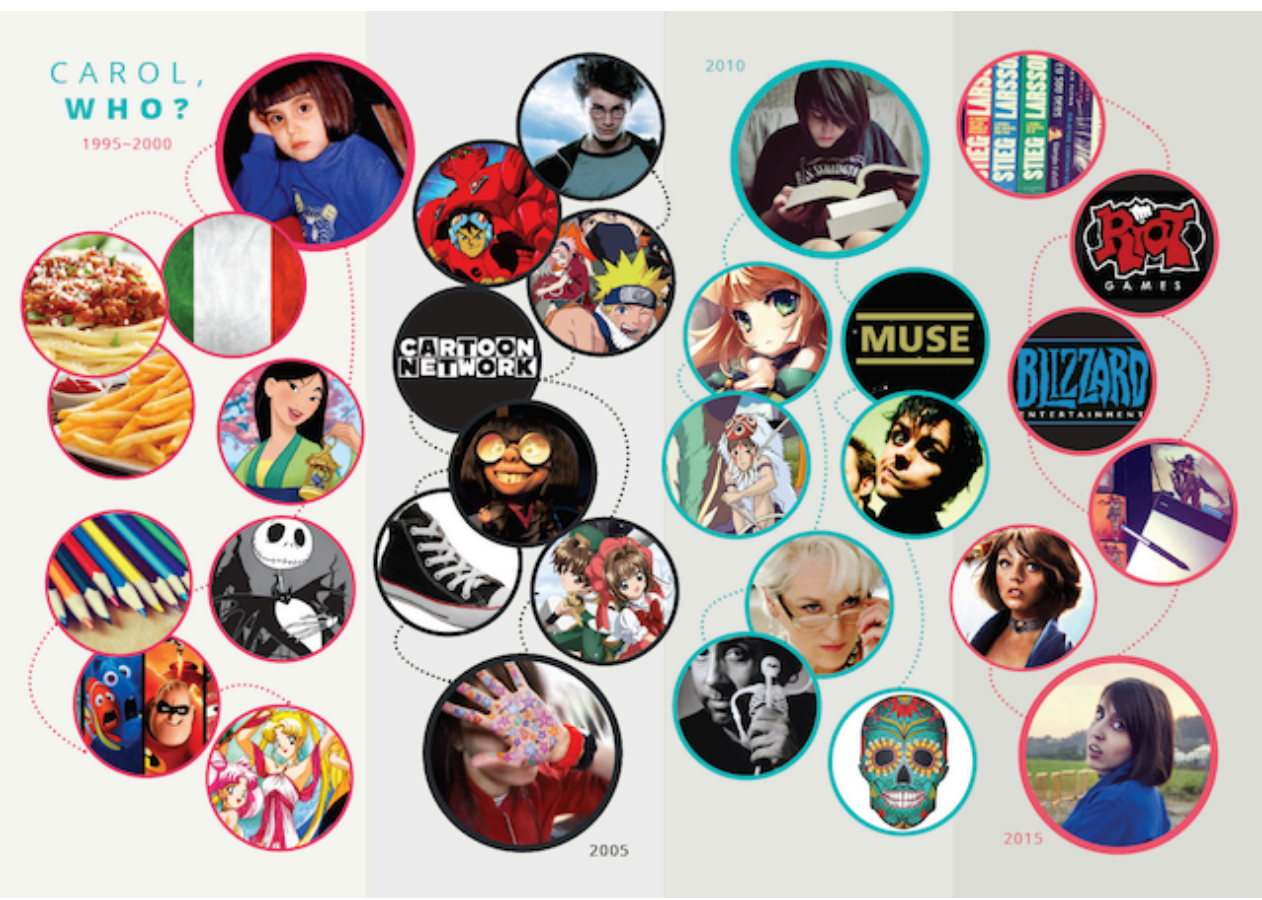

Fonte: Imagem elaborada pelos autores 
Figura 2 - Cenário mais emocional

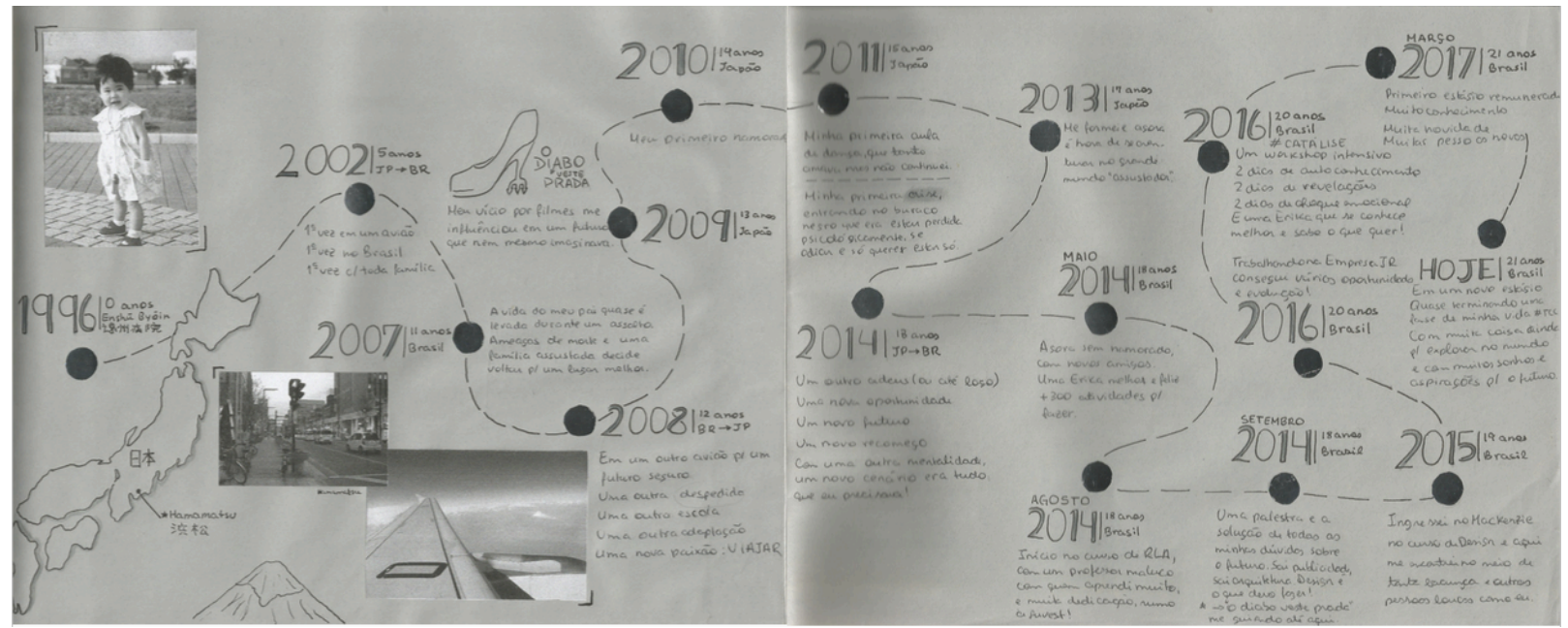

Fonte: Imagem elaborada pelos autores

As respostas às três questões mencionadas acima, são transformadas e sintetizadas em palavras, e posteriormente colocadas lado a lado, para que os alunos consigam ver quais se repetem. Esta repetição é importante para encontrar a definição das verdadeiras e mais relevantes características, a partir disso, as palavras se transformarão em um painel de expressão.

Figura 3 - Processo de verificação das palavras

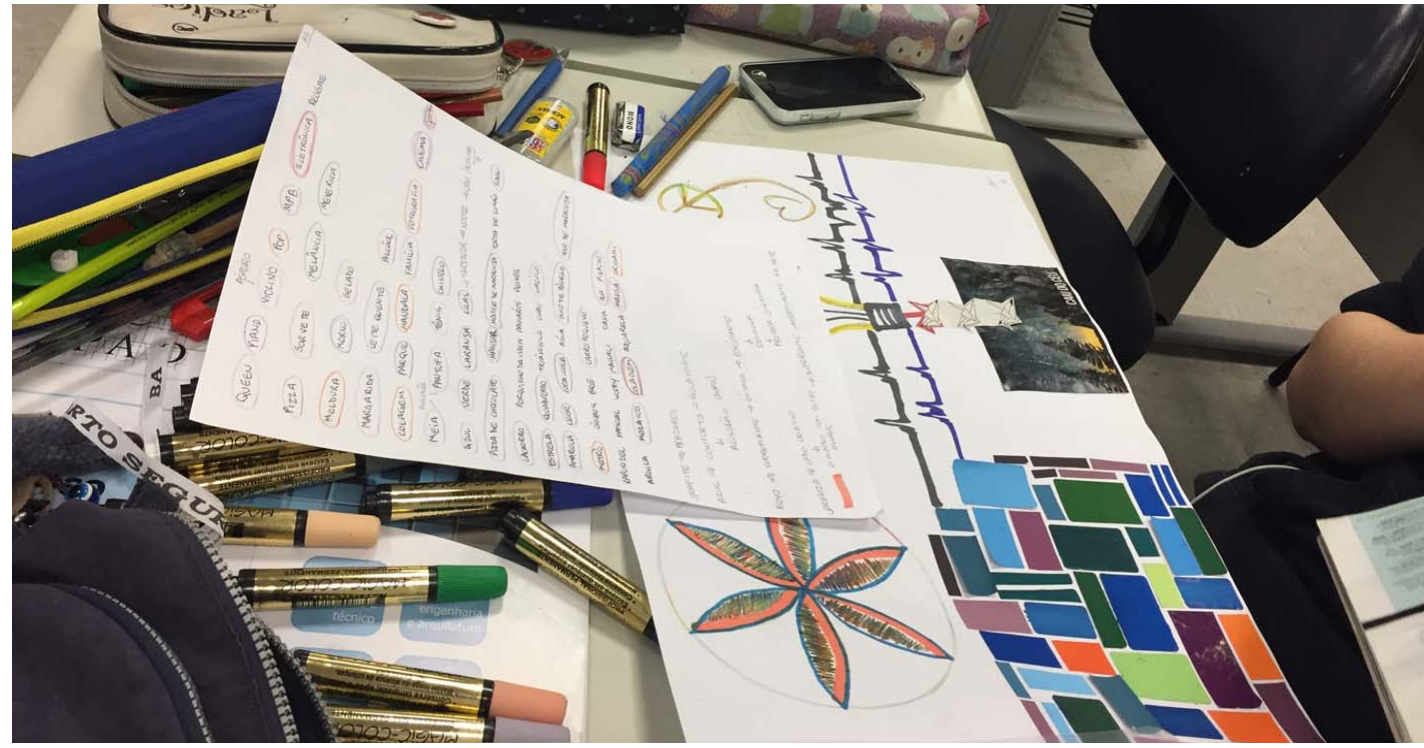

Fonte: Imagem elaborada pelos autores

Em paralelo, os alunos elaboram um outro painel dos seus gostos de comida, hobby, música, literatura e esporte; além disso, eles colocam as idealizações de futuro na área do design e marcas pessoais de referência com uma breve análise das mesmas. Abaixo um exemplo desta fase. 
Figura 4 - Painéis de referências de gostos pessoais
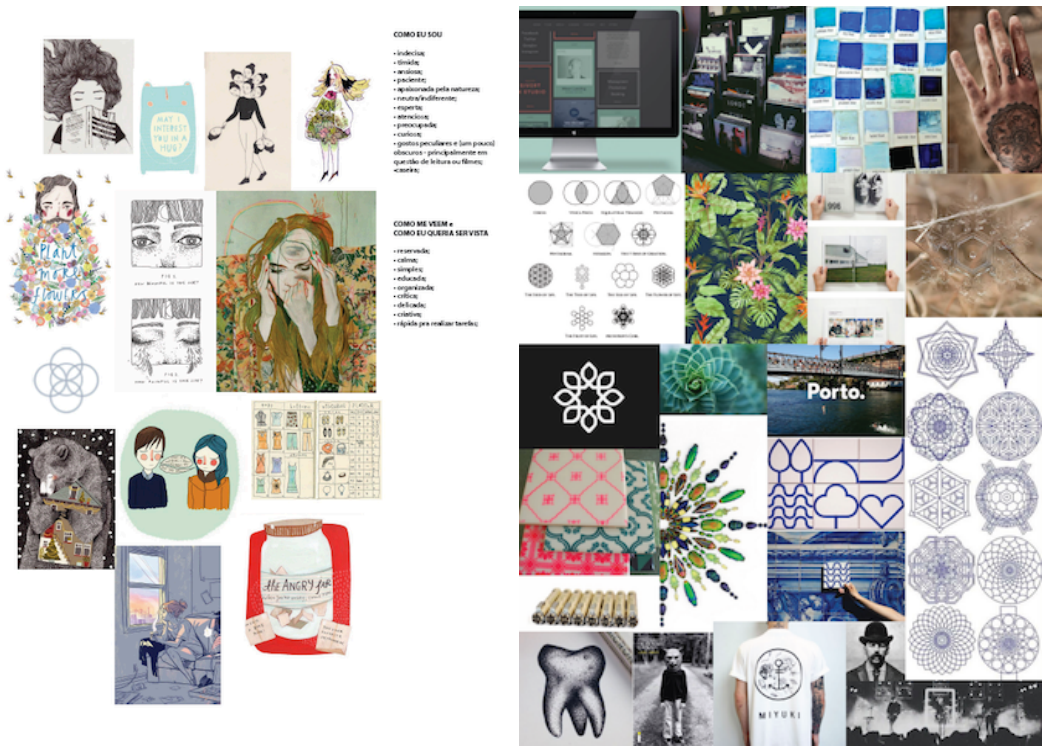

Fonte: Imagem elaborada pelos autores

A segunda etapa é a fase de concepção do projeto, o encontro do caminho ou linguagem visual que conduzirá os estudos e simbologias da marca pessoal. Para isso, é necessário ampliar ou detalhar melhor os painéis semânticos elaborados anteriormente, pois este processo de certa forma conduz a reflexão do que é realmente importante sintetizar e apresentar na marca. A condução é o desenvolvimento de três painéis semânticos específicos, o primeiro é o de estilo visual, os alunos são levados a olhar os cenários desenvolvidos e sintetizá-los. O segundo painel é de expressão visual, este painel concentra a sensação ou emoção que se quer expressar na marca, é importante encontrar palavras chave, tiradas das respostas às questões iniciais. Geralmente os alunos elaboram painéis bem distintos, dois exemplos abaixo mostram caminhos específicos, um caminho mais linear exemplificado na figura 5, e o outro em forma de composição e que estabelece uma relação da ousadia que a marca terá, como mostra a figura 6.

Figura 5 - Painel de expressão detalhado
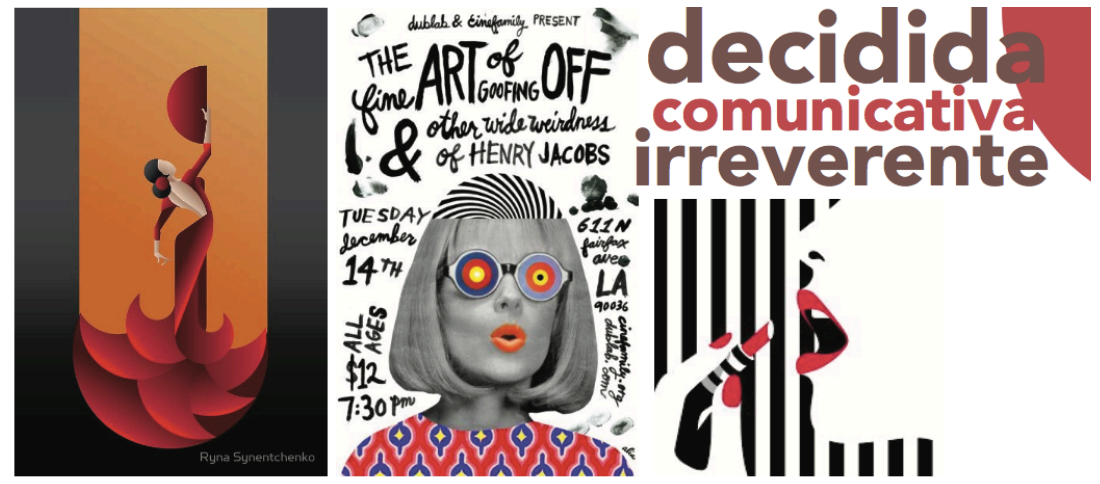

comunicativa adjetivo - que se comunica facilmente, franco, expansivo, afável, riso comunicativo, pessoa comunicativa.

decidida adjetivo - convicto em seus (próprios) objetivos e propósitos, determinado: ele sempre foi um sujeito decidido.

irreverente adjetivo de dois generos: alguém que vive a vida do seu jeito e procura a sua felicidade sem se importar com costumes/tradiçôes estabelecidos pela sociedade. Alguém desinibido e bem disposto, com sentido de humo 
Figura 6 - Painel de expressão sintetizado

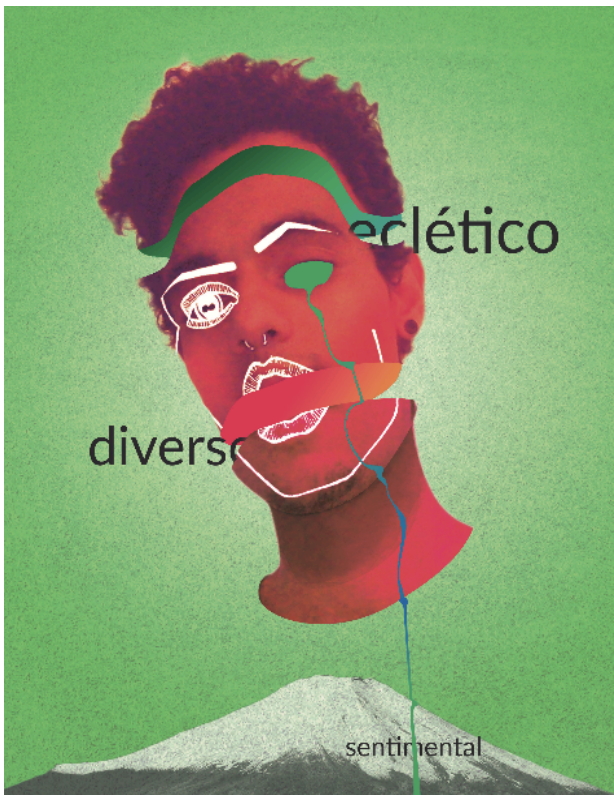

Fonte: Imagem elaborada pelos autores

O último painel é o conceitual, ele se baseia nos painéis de referência e de expressão, deve conter a linguagem visual que conduzirá a elaboração dos estudos, a tipografia, paleta de cores e seus significados, grafismos e desenhos, os elementos simbólicos que estão presentes nos cenários. Além disso, os testes de tipografia devem ser elaborados no naming que será utilizado na marca. Para isso, solicita-se que seja feito um brainstorming de possibilidades de nomes, levando em consideração o nome completo, abreviação, as iniciais, apelido, ou um nome fantasia. Com o naming definido, parte-se para a pesquisa de tipografias, ou o desenvolvimento de um lettering, desenhar o naming, que pode ser baseado na própria assinatura ou numa tipografia manuscrita. A figura abaixo mostra um exemplo do encontro do naming através da síntese dos dois nomes de uma aluna.

Figura 7 - Encontro do naming

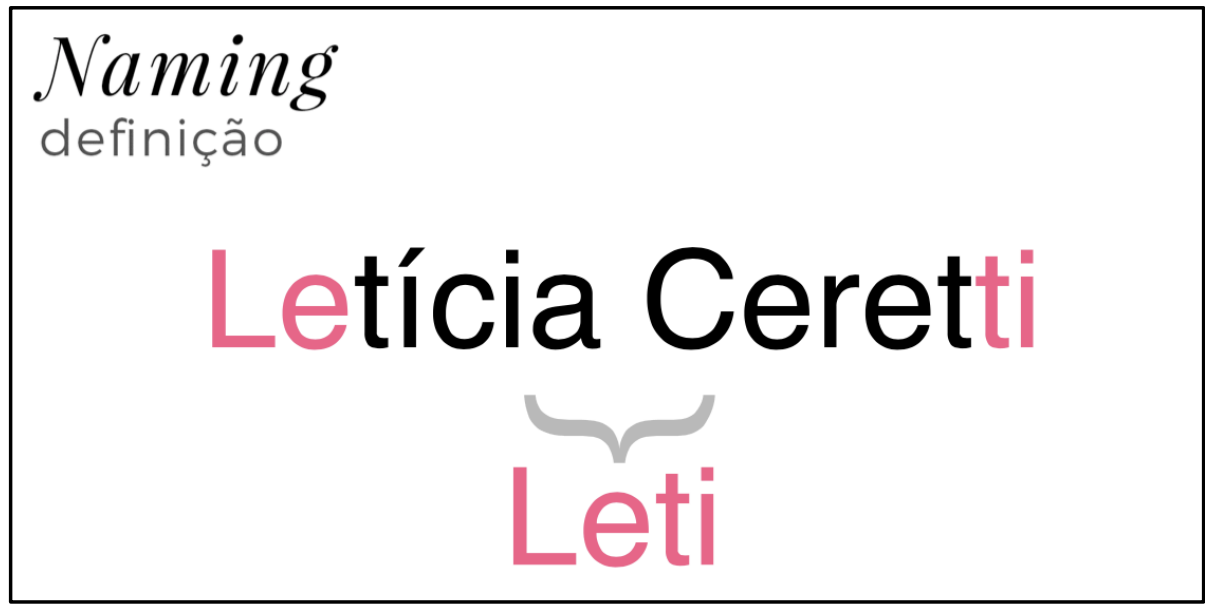

Fonte: Imagem elaborada pelos autores 
O painel conceitual também deve conter a plataforma de marca do aluno, constituída de sua essência (seu DNA), seus pilares que são os valores e princípios, e atributos relacionados a cada item dos pilares. Abaixo um exemplo de plataforma da marca.

Figura 8 - Plataforma da Marca de uma marca pessoal

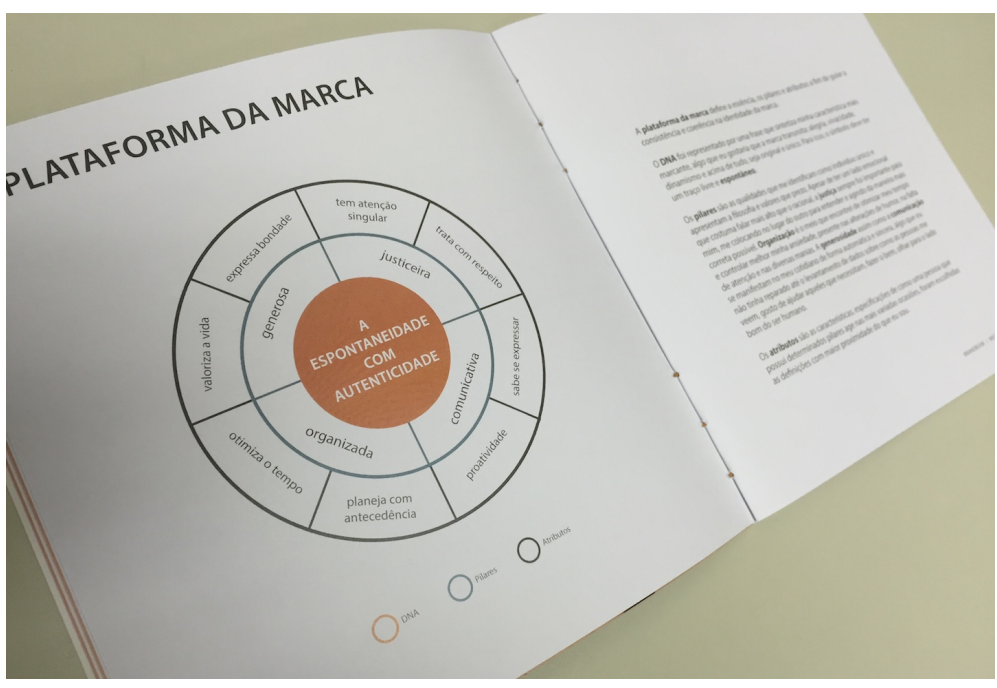

Fonte: Imagem feita pelos autores

Em seguida, é dado início ao desenvolvimento dos roughs, estudos da marca, a intuição deve ser estimulada para que se encontre o caminho ideal. Geralmente os estudos iniciais são tímidos, mas aos poucos os alunos vão se soltando, tanto o cenário como os painéis devem estar em cima da mesa, a observação desse levantamento estimula as idéias, as conexões, e principalmente os links, é necessário que eles percebam e façam as conexões, e posteriormente possam justificar e defender a escolha da proposta. As figuras abaixo mostram como os alunos desenvolvem os estudos com auxílio dos painéis semânticos.

Figura 9 - Início dos estudos da marca

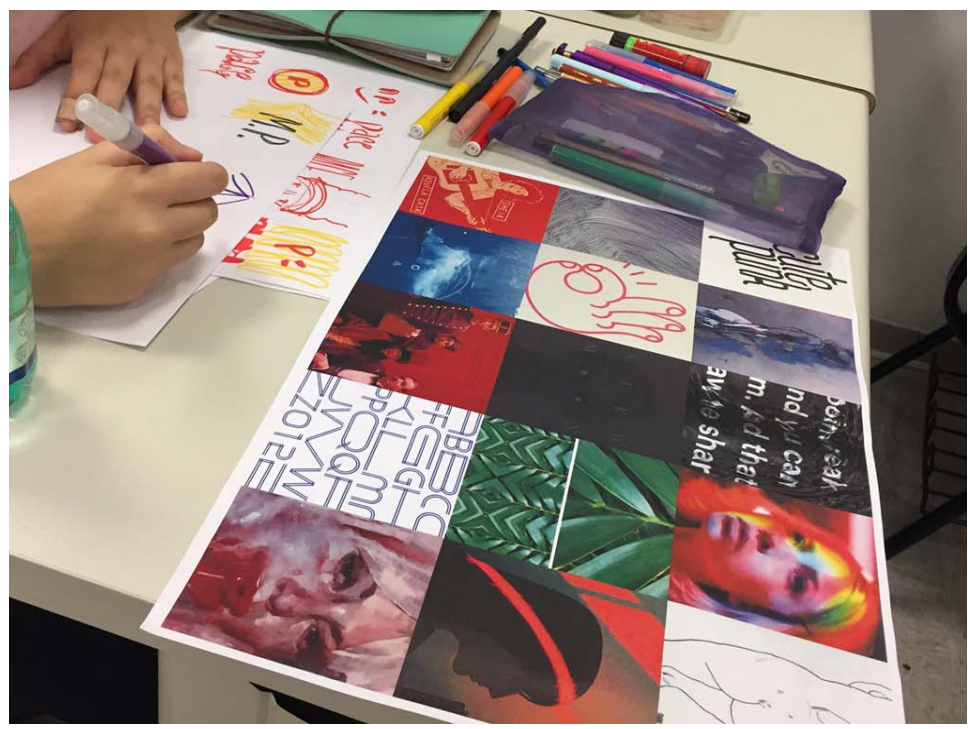

Fonte: Imagem feita pelos autores 
Figura 10 - desenvolvimento dos estudos da marca

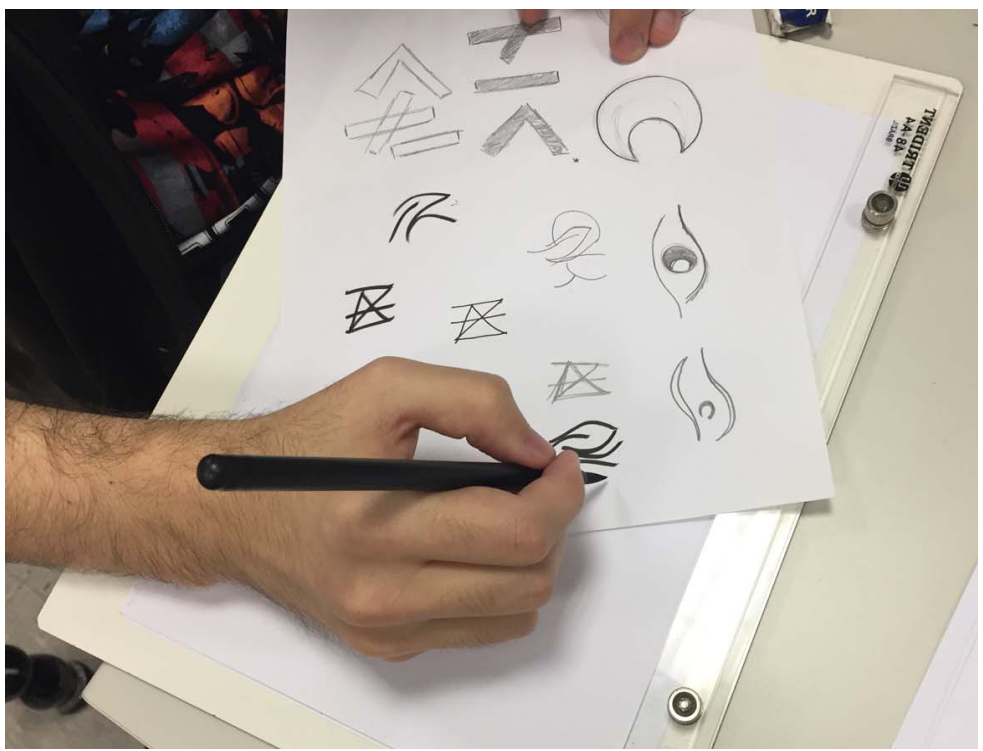

Fonte: Imagem feita pelos autores

A terceira e última etapa, é a construção da identidade, o sistema de códigos que estarão presentes com a proposta da marca, a família tipográfica escolhida, a paleta de cores, o grafismo, e as versões e desdobramentos da marca. A partir disso, o processo é mais técnico, pois a proposta da marca necessita de acertos estruturais no desenho, a construção de uma malha de curvas no caso das marcas gestuais ou que possuem formas orgânicas, e a definição de um grid para definir as proporções entre símbolo e naming, e ajustar as marcas com configurações geométricas. Nesta fase é necessário experimentar a proposta em aplicações básicas, como a papelaria, e aplicações mais ousadas, como um currículo, site ou portfólio.

Figura 11 - pranchas e a estrutura técnica de várias marcas pessoais

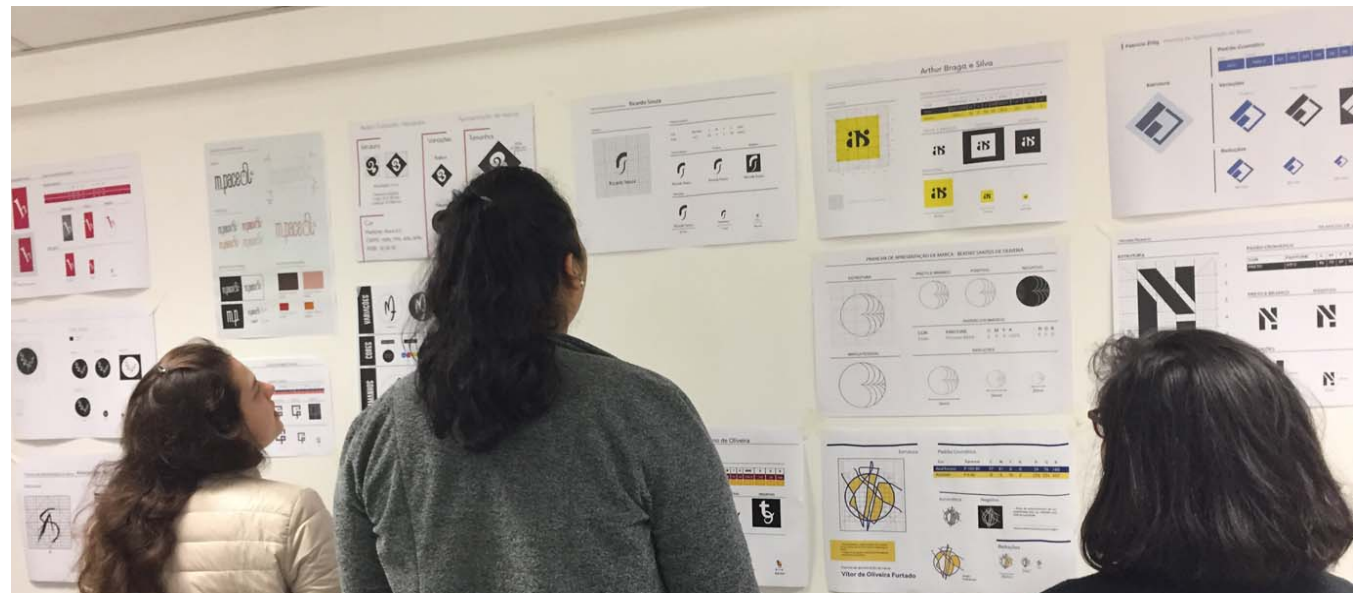

Fonte: Imagem feita pelos autores

A apresentação do projeto ocorre individualmente, o procedimento é de duas formas, uma digital, onde o processo e resultado deve ser detalhado sucintamente; e apresentação do manual de identidade visual ou brandbook impresso, que segundo Alina Wheeler (2012), é o livro da 
marca, guarda a essência da marca, tem como função esclarecer o conceito e filosofia da marca, apresentado-a como um organismo vivo, fortalecendo a personalidade, linguagem e características próprias. O brandbook deve conter a filosofia e expressão da marca de maneira poética e conceitual, isto é, o formato e diagramação espelham a linguagem visual da marca.

Figura 12 - manuais de identidade visual de várias marcas pessoais

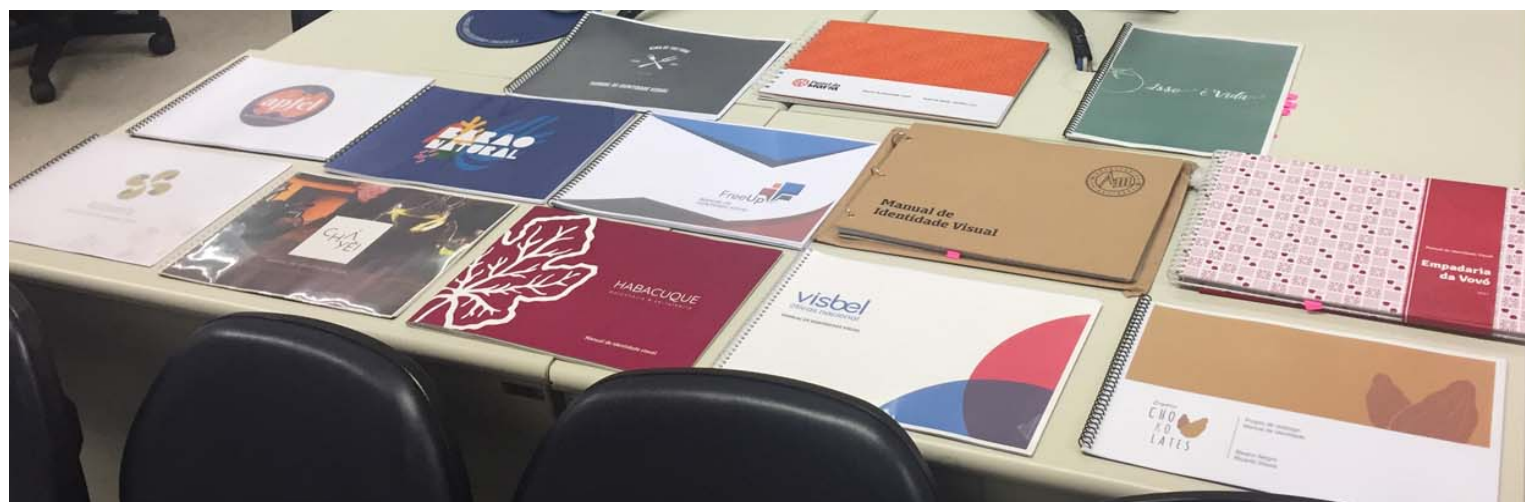

Fonte: Imagem feita pelos autores

Figura 13 - Brandbook e manual de uma mesma marca pessoal

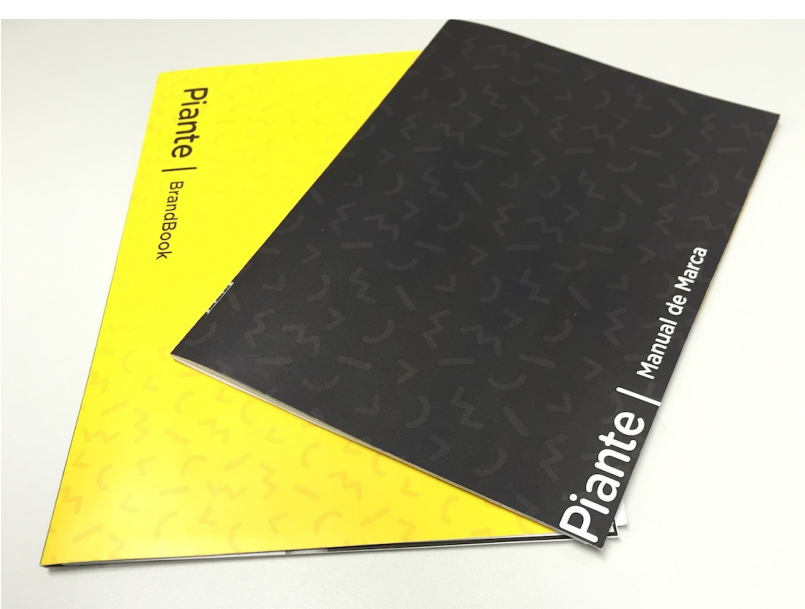

Fonte: Imagem elaborada pelos autores

Recentemente testou-se um processo específico, que tem como ponto de partida as duas perguntas: o que eu sou? E o que me forma? Aqui os alunos trabalham com a colocação de muitos elementos dentro de uma silhueta. Inicialmente eles pedem ajuda a outro colega para desenharem a sua silhueta, a partir disso, com qualquer forma de expressão e material, eles configuram o painel pessoal no limite da própria silhueta. Este procedimento leva naturalmente o aluno a se despir e deixar aparecer um pouco de que naquele momento é a sua expressão. Em seguida, todas as silhuetas são colocadas ao redor da sala e durante uma aula inteira, cerca de 4 horas de conversa, são feitas as perguntas: alguém quer falar do seu trabalho, ou quer falar de algum trabalho da sala? Isso dá início a uma grande conversa, um fala do outro, todos falam de si, igualdades e diferenças, discute-se o conjunto e a parte, o indivíduo e o coletivo. Percebem-se os grupos, tendências, modismos, falas que são próprias e falas que se repetem de outras pessoas, 
influências positivas e negativas. Detectou-se que este procedimento de reflexão em conjunto dá uma certa segurança de trabalhar no tema da marca pessoal. Posteriormente começa-se a desenvolver painéis individuais como exposto anteriormente, música, hobby, comida, etc. Depois é feito a leitura do texto do Delano Rodrigues (2011), naming, para dar profundidade e metodologia de criação ao encontro do nome que é parte fundamental para a identidade. Em seguida, o processo segue conforme detalhado na segunda e terceira parte do procedimento anterior exposto acima.

Figura 14 - Começo dos cenários pessoais com as silhuetas dos alunos

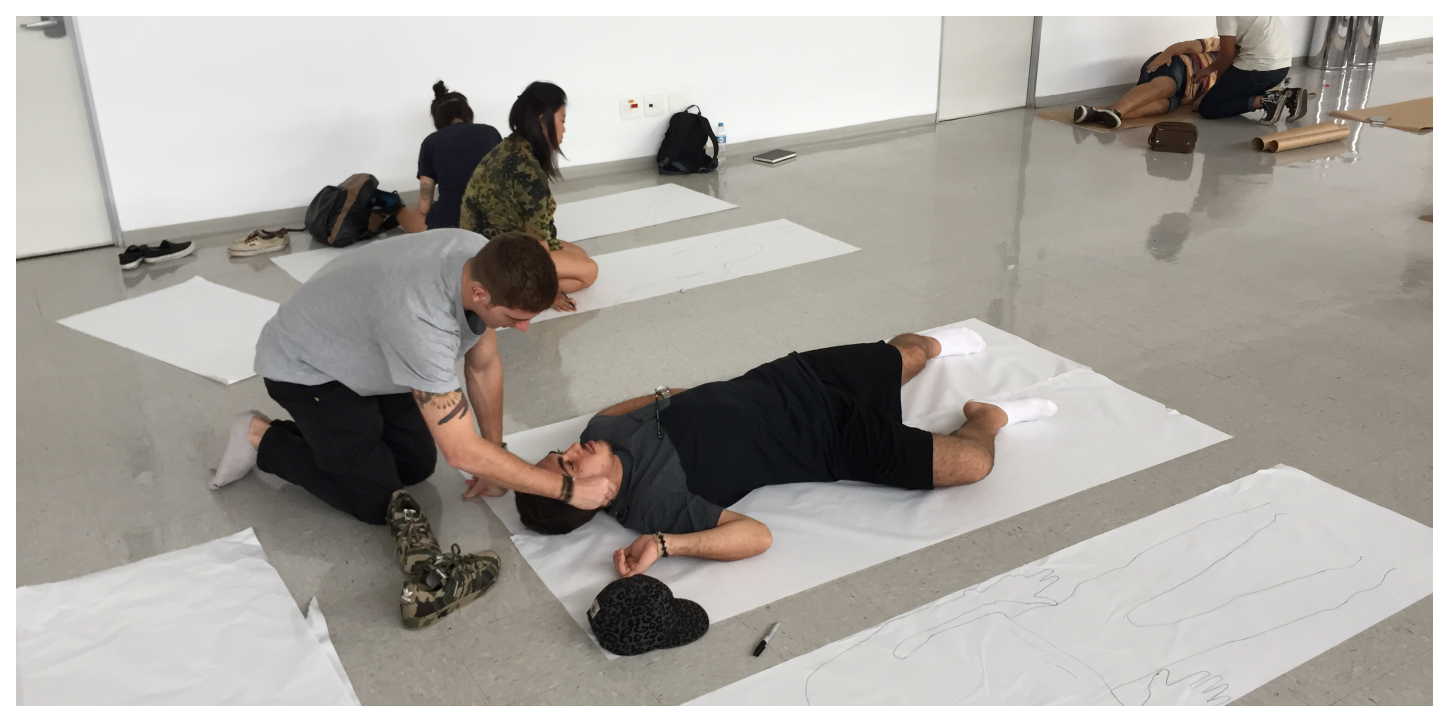

Fonte: Imagem elaborada pelos autores

Figura 14 - Término dos cenários pessoais com as silhuetas dos alunos

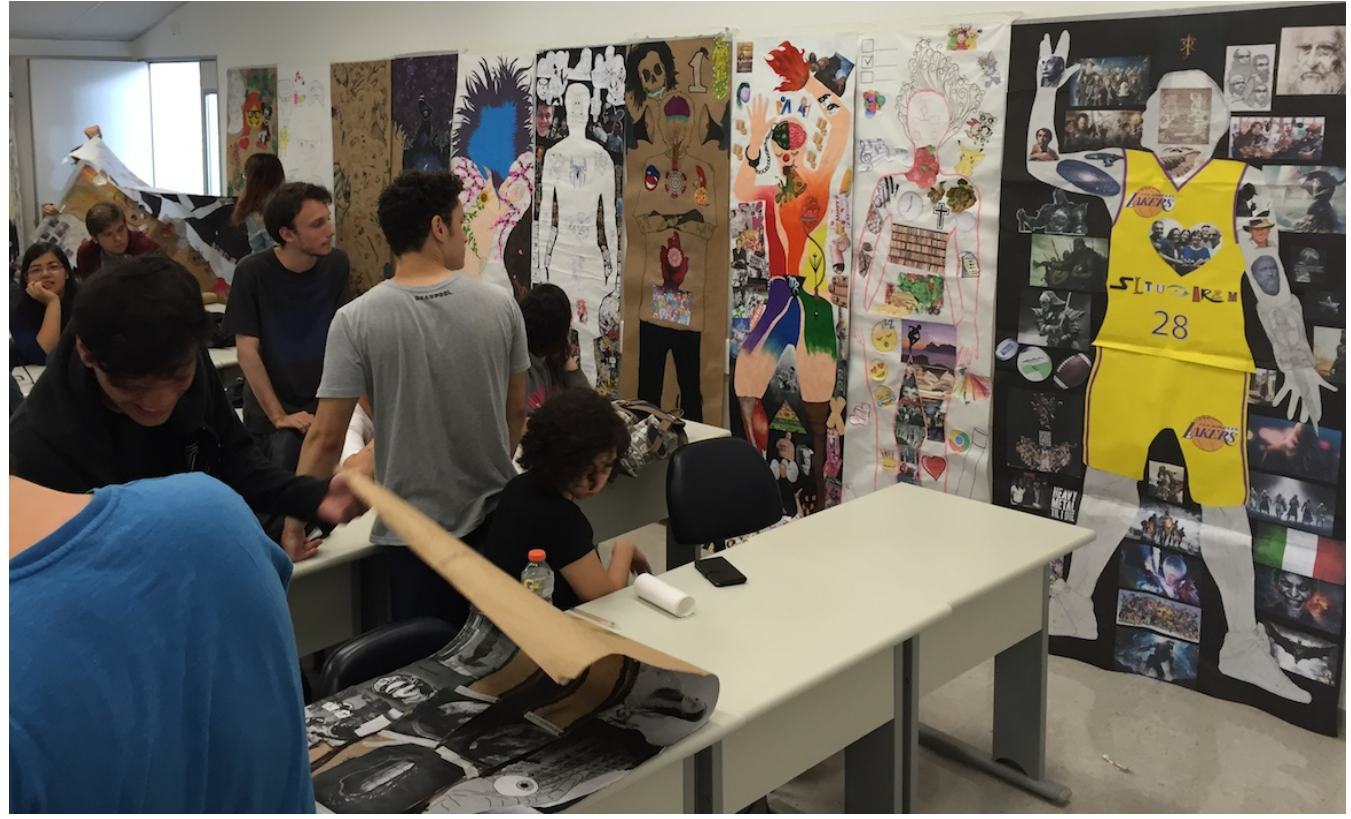

Fonte: Imagem elaborada pelos autores 


\section{Conclusão}

Ao longo destes dez anos de desenvolvimento do projeto de marca pessoal na disciplina de identidade, o processo passou por modificações e evoluiu em vários sentidos, dentre os quais a questão metodológica e o critério de avaliação dos resultados obtidos, diante das reações dos alunos e suas percepções pessoais ao se depararem com as críticas para a melhoria de suas marcas. Um outro aspecto importante no aprimoramento da disciplina foi em decorrência das mudanças de estrutura nos cursos de design de maneira geral, e o papel da disciplina de projeto no curso. É notório que esta disciplina tem um papel relevante no mercado de trabalho, percebese que a maioria dos projetos de design gráfico necessitam de uma identidade, seja por conta de um logotipo, sinal gráfico, ou estrutura de códigos visuais destinados a atender os sistemas de comunicação. E segundo Alina Wheeler, "Os empregos não duram mais para sempre. O número de indivíduos autônomos aumentou drasticamente durante a última década. Hoje um terço da força de trabalho americana é autônoma."(WHEELER, 2012, p.90)

Mas o aspecto fundamental para a evolução e mudanças no projeto foi o tempo de desenvolvimento, que inicialmente era realizado em um mês, posteriormente passou a ser de 45 dias, e hoje ele acontece em 4 meses, pois faz parte da estrutura de uma oficina de marca pessoal. A alteração pontual no processo, do tempo mínimo ao máximo, é distribuída no tempo e amadurecimento de cada etapa. A maior e mais importante contribuição para a evolução do processo da construção da marca pessoal, vem das avaliações elaboradas pelos alunos ao final do desenvolvimento do projeto, quando é realizado um bate-papo para o levantamento das críticas e contribuições dos mesmos, é um momento crucial em que os docentes se colocam à disposição para ouvir o que foi positivo no processo, e o que foi problemático.

Finalizando, a reflexão percebida nestes últimos anos da postura de ex-alunos atuantes no mercado nacional e internacional que vivenciaram este processo, transparece uma certa segurança e determinação na sua atitude como designer, refletindo a construção de identidades marcantes.

É interessante observar que a necessidade de se ter uma marca pessoal é aparentemente uma necessidade da contemporaneidade, onde os indivíduos estão a todo momento buscando um significado para a sua existência. Vivemos várias identidades no nosso cotidiano, diante de múltiplas escolhas somos levados a experimentar possibilidades através do consumo de objetos e serviços. E segundo Joan Costa (2008), a evolução da marca vem de um processo significativo e simbólico desde a Antiguidade.

A marca começou sendo uma coisa: um signo (Antigüidade). Depois foi um discurso (Idade Media). A seguir, um sistema de memória (economia industrial). Atualmente, a marca é um fenômeno complexo (economia da informação, cultura de serviço, sociedade do conhecimento). A crescente complexidade, tanto do nosso ambiente material e tecnológico, como de nosso sistema social, econômico, político e legal, constitui-se em um imenso aparelho gerador de micro e macro transformações, não só no ambiente material, mas também, é lógico, no ambiente social e cultural. (COSTA, 2008, p. 91)

\section{Referências}

BAUMAN, Zygmunt. Identidade: entrevista a Benedetto Vecchi. Rio de Janeiro, Jorge Zahar, 2005. 
COSTA, Joan. A imagem da marca. Um fenômeno social. São Paulo, Rosari, 2008.

FUENTES, Rodolfo. A prática do design gráfico: uma metodologia criativa. São Paulo, Rosari, 2006.

JUNG, Carl G. O homem e seus símbolos. Rio de Janeiro: Editora Nova Fronteira, 1983.

NEUMEIER, M. The Brand Gap = O Abismo da Marca: como construir a ponte entre a estratégia e o design. Porto Alegre: Bookman, 2008.

RODRIGUES, Delano. Naming: o nome da marca. Rio de Janeiro: 2AB, 2011.

WHEELER, Alina. Design de identidade da marca: guia essencial para toda a equipe de gestão de marcas. Porto Alegue: Bookman, 2012. 